\title{
Do signo ao texto, da língua ao discurso: de Saussure a Charaudeau
}

\author{
Ilana Silva Rebello ${ }^{a}$
}

\begin{abstract}
Resumo
Este artigo, num primeiro momento, tem por objetivo tecer algumas reflexões a respeito do conceito de signo linguístico postulado por Saussure para, a partir dessa abordagem, visitar outras que aprofundaram e ampliaram os estudos do linguista suiço, como as definições arroladas por Hjelmslev, Ullmann e Pottier. Após essa abordagem estruturalista, num segundo momento, busca-se um vínculo entre as ideais de Saussure e as propostas do analista do discurso, Patrick Charaudeau, na distinção entre sentido de lingua e sentido de discurso. Este estudo é importante, tendo em vista que a problemática envolvendo a leitura de qualquer texto, ou seja, a atividade "da língua ao discurso" passa, inevitavelmente, pela concepção do signo linguístico, que recebe enfoques distintos, em variadas correntes.

Palavras-chave: Signo. Língua. Discurso. Leitura.
\end{abstract}

Recebido em 30/08/2017

Aceito em 26/12/2017

a Professora de Língua Portuguesa do Departamento de Letras Clássicas e Vernáculas da Universidade Federal Fluminense. E-mail: ilanarebello@id.uff.br 
Todos estão cercados por uma infinidade de signos. Cada vez mais as pessoas são levadas a compreender diferentes signos, a descobrir como interagem com os objetos, como pensam e se emocionam. Linguagem verbal e não verbal se misturam. Na fotografia, no cinema, no rádio, na televisão, nos hipertextos, na hipermídia, enfim, tudo é linguagem, tudo é signo.

Ao mesmo tempo em que novos signos são criados, surge a necessidade de que possamos lê-los, ou seja, refletir a respeito do que eles significam em um nível um pouco mais profundo do que aquele que nasce da mera convivência e familiaridade. Nem tudo é só o que aparenta ser. Uma palavra pode dizer muito mais do que o seu sentido literal. Da mesma forma, uma imagem pode revelar muitas informações, muitas mensagens nas suas cores, formas, linhas...

Atualmente, a definição de signo está relacionada com diferentes concepções, dentre as quais a principal é a do linguista suíço Ferdinand de Saussure (1857-1913), fundador da linguística moderna e introdutor dos princípios fundamentais da semiologia.

\section{Saussure e o conceito de signo dicotômico}

Enquanto alguns estudiosos trabalham com o signo, em geral, ou seja, tudo pode ser um signo, Saussure trabalha apenas com o signo verbal, ou seja, com o signo linguístico.

Em seu Curso de linguística geral, Saussure (1977) define o signo linguístico como a combinação do conceito e da imagem acústica (p. 81). Mais adiante, o linguista substitui os termos conceito e imagem acústica por significado e significante, respectivamente: "Propomo-nos a conservar o termo signo para designar o total, e a substituir conceito e imagem acústica respectivamente por significado e significante."

Figura 1. Signo

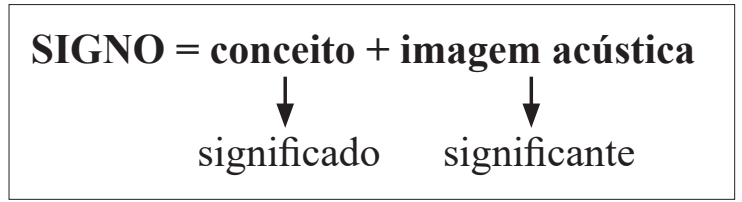


Um dos exemplos dados pelo autor foi o da palavra "árvore". Essa palavra é constituída pelo seu aspecto concreto, seu conjunto sonoro (significante) e por seu aspecto conceitual, abstrato, a imagem mental (significado).

Dessa forma, deduz-se que signo é a união do significante + significado, que representa ou traduz para alguém uma visão segmentada e arbitrária da realidade designada. Ou seja, para Saussure, o signo é um elemento em que se correlacionam apenas dois outros elementos - significante e significado. E o significado não é uma coisa em si, mas a interpretação que o sistema linguístico faz dela. Nesse sentido, o linguista rompe com a ideia de que as palavras corresponderiam às coisas do mundo, como se fossem etiquetas preestabelecidas.

O signo linguístico une não uma coisa e uma palavra, mas um conceito e uma imagem acústica. Esta não é o som material, coisa puramente física, mas a impressão (empreinte) psíquica desse som, a representação que dele nos dá o testemunho de nossos sentidos; tal imagem é sensorial e, se chegamos a chamá-la "material", é somente neste sentido, e por oposição ao outro termo da associação, o conceito, geralmente mais abstrato. (SAUSSURE, 1977, p. 80)

Ao afirmar que a língua não é uma nomenclatura da realidade, o linguista genebrino mostrava que a língua não reflete pura e simplesmente a realidade, mas, ao contrário, faz uma interpretação desta. Daí também que o mundo é categorizado de forma diferente pelos diversos sistemas linguísticos.

Se as palavras estivessem encarregadas de representar os conceitos dados de antemão, cada uma delas teria, de uma língua para outra, correspondentes exatos para o sentido; mas não ocorre assim. O francês diz indiferentemente louer (une maison) e o português alugar, para significar dar ou tomar em aluguel, enquanto o alemão emprega dois termos, mieten e vermieten; não há, pois, correspondência exata de valores. (...) (SAUSSURE, 1977, p. 135)

O objeto do significado é um componente levado pelo significante. $\mathrm{O}$ processo que liga as duas faces - imagem acústica (significante) e conceito (significado) - é chamado de significação.

Outra concepção relevante nas teses de Saussure é a ideia de dois eixos da linguagem: o do sintagma e o da associação. Quando se postula que nenhuma mensagem tem sentido por 
si só, afirma-se que os elementos dependem uns dos outros para significarem. Saussure $(1977$, p. 132) já mostrava que a significação se ancora na noção de valor, pois “(...) a ideia de valor, assim determinada, nos mostra que é uma grande ilusão considerar um termo simplesmente como a união de certo som com um certo conceito. Defini-lo assim seria isolá-lo do Sistema do qual faz parte (...)".

Assim expõe Almeida (2011, p. 34), a respeito da noção de valor postulada por Saussure: "Justa conclusão que influenciou diretamente linguistas posteriores a verem na rede de relações a única fonte para o estudo do significado da língua, dispensando assim outras perspectivas do significado."

Dessa forma, o contexto é de grande importância na interpretação de enunciados. Ainda segundo Saussure (1977, p. 135),

(...) o valor de qualquer termo que seja está determinado por aquilo que o rodeia; nem sequer da palavra que significa "sol" se pode fixar imediatamente o valor sem levar em conta o que lhe existe em redor; línguas há em que é impossível dizer "sentar-se ao sol".

Nesse sentido, para uma palavra pouco importa o conceito literal que denota. Além da significação, a noção de "valor" é muito importante para a percepção da virtual inexistência de sinônimos perfeitos numa língua, tendo em vista que determinados matizes semânticos implicam usos distintos e nem sempre encontram correspondentes em outras línguas.

Para Saussure (1977, p. 133), o valor de um signo resulta da presença simultânea de outros signos dentro do sistema aos quais ele se contrapõe, formando uma rede semântica. Aos vocábulos que integram essa rede de significações ele dá o nome de campo semântico dessa palavra.

As teses de Saussure foram aprofundadas por diferentes linguistas e analistas do discurso. Veremos, de forma sucinta, alguns desses aprofundamentos.

\section{Hjelmslev e os conceitos de forma e substância}

As teses de Saussure foram aprofundadas pelo linguista dinamarquês Louis Trolle Hjelmslev, em sua principal obra, Prolegômenos a uma teoria da linguagem, publicada originalmente em 1943. 
O linguista dinamarquês, em seus estudos, conservou duas afirmações centrais de Saussure: a língua não é substância, mas forma; e toda língua é ao mesmo tempo expressão e conteúdo. Para o linguista, "considerado isoladamente, signo algum tem significação. Toda significação de signo nasce de um contexto, quer entendamos por isso um contexto de situação ou um contexto explícito" (HJELMSLEV, 1975, p. 50).

À noção de signo, Hjelmslev introduziu uma distinção importante para o estudo não apenas do signo linguístico, mas também do signo semiológico. Para o linguista, cada plano o dos significantes (plano de expressão) e o dos significados (plano de conteúdo) - comporta dois strata: a forma e a substância.

Barthes (1971, p. 43), abordando a teoria de Hjelmslev, define forma como o que pode ser descrito de forma exaustiva, simples e coerente pela Linguística, sem a necessidade de se recorrer a premissas extralinguísticas; e substância, ao contrário, como o conjunto dos aspectos dos fenômenos linguísticos que não podem ser descritos sem a ajuda de premissas extralinguísticas. Em outras palavras, há uma substância da expressão (substância fônica, articulatória, por exemplo), uma forma da expressão (as regras paradigmáticas e sintáticas, por exemplo), uma substância de conteúdo (aspectos emotivos, ideológicos ou simplesmente nocionais do significado, por exemplo) e uma forma do conteúdo (organização formal dos significados entre si, por ausência ou presença de uma marca semântica).

Figura 2. Concepção de signo de Hjelmslev

\begin{tabular}{|c|c|c|}
\hline \multicolumn{2}{|c|}{ Matéria de conteúdo } & \\
\hline \multirow{2}{*}{ Plano do conteúdo } & Substância do conteúdo & \\
\hline & Forma de conteúdo & \multirow{2}{*}{$\begin{array}{c}\text { Signo } \\
\text { linguístico }\end{array}$} \\
\hline \multirow{2}{*}{ Plano de expressão } & Forma de expressão & \\
\hline & Substância de expressão & \\
\hline \multicolumn{3}{|c|}{ Matéria de expressão } \\
\hline
\end{tabular}

Fonte: Almeida (2011, p. 44). Adaptado de Lopes (1995, p. 95) 
Além da noção de forma e substância, Hjelmslev (1975, p. 205-210) introduziu o conceito de matéria de conteúdo e matéria de expressão como sinalizado na figura anterior. Para o linguista, a matéria de conteúdo é o contínuo amorfo e não analisável no qual as fronteiras são colocadas na formação das línguas; e a matéria de expressão são as condições funcionais oferecidas pela língua, as capacidades humanas de articulação dos sons que formam os diversos sistemas fonológicos.

Hjelmslev (1975, p. 80) ainda afirma que a língua é uma forma e que fora dessa forma existe uma matéria não linguística, a "substância" saussuriana - o sentido. Esse sentido, para o autor, seria uma grandeza não analisável, no entanto, passível de análise do ponto de vista lógico, psicológico etc., e é ordenado, articulado e formado de maneira diferente nas diversas línguas.

O linguista cita como exemplo as seguintes sequências que, em português, podem ser traduzidas como "Eu não sei":

Jeg véd det ikke (dinamarquês)

I do not know (inglês)

Je ne sais pas (francês)

Em tiedä (filândês)

Naluvara (esquimó)

(HJELMSLEV, 1975, p. 56)

Todos os enunciados acima têm um fator em comum, o sentido, apesar de apresentarem formas diferentes em cada língua. Portanto, no conteúdo linguístico, há uma forma específica, a forma do conteúdo, que é independente do sentido com o qual ela se mantém numa relação arbitrária e que ela transforma em substância do conteúdo.

Além dos conceitos de forma e substância, outra contribuição importante do linguista dinamarquês para o nosso estudo é a distinção entre denotação e conotação. Hjelmslev fala em semiótica denotativa (nenhum dos dois planos - conteúdo e expressão - é uma semiótica) e, a partir dessa semiótica, distingue mais duas: a semiótica conotativa (cujo plano de expressão é uma semiótica) e a metassemiótica (cujo plano de conteúdo é uma semiótica). 
Figura 3. Conotação x Metalinguagem

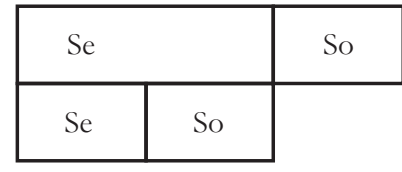

Conotação

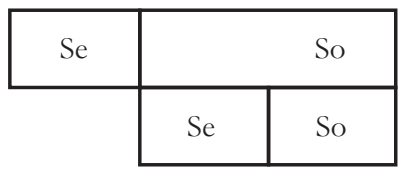

Metalinguagem

Fonte: Barthes, 1971, p. 96.

Figura 4. Conotação x Denotação x Sistema Real

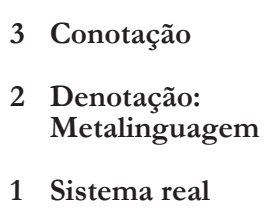

1 Sistema real

\begin{tabular}{|c|c|c|c|}
\hline \multicolumn{3}{|c|}{ Se : Retórica } & So : Ideologia \\
\hline \multirow[t]{2}{*}{ Se } & & So & \\
\hline & & So & \\
\hline
\end{tabular}

Fonte: Barthes, 1971, p. 98.

Barthes (1971, p. 95-99), sobre a distinção acima proposta por Hjelmslev, tece várias considerações, dentre as quais destacamos:

(...) um sistema conotado é um sistema cujo plano de expressão é, ele próprio, constituído por um sistema de significação; (...) (p. 95);

(...) uma metalinguagem é um sistema cujo plano do conteúdo é, ele próprio, constituído por um sistema de significação; ou ainda, é uma Semiótica que trata de uma Semiótica. (...) (p. 96)

(...) A conotação, por ser ela própria um sistema, compreende significantes, significados e o processo que une uns aos outros (significação), e é o inventário destes três elementos que se deveria primeiro empreender para cada sistema. Os significantes de conotação, que chamaremos conotadores, são constituídos por signos (significantes e significados reunidos) do sistema denotado; naturalmente, vários signos denotados podem reunir-se para formar um só conotador se for provido de um só significado de conotação; ou melhor, as unidades do sistema conotado não têm forçosamente o mesmo tamanho que as unidades do sistema denotado; grandes fragmentos de discurso denotado podem constituir uma única unidade do sistema conotado (...). Seja qual for o modo pelo qual a conotação "vista" a mensagem denotada, 
ela não a esgota; sempre sobra "denotado" (sem o quê o discurso não seria possível) e os conotadores, afinal são sempre signos descontínuos, "erráticos", naturalizados pela mensagem denotada que os veicula. Quanto ao significado de conotação, tem um caráter ao mesmo tempo geral, global e difuso: é, se se quiser, um fragmento de ideologia: (...) a ideologia seria, em suma, a forma (no sentido hjelmsleviano) dos significados de conotação, enquanto a retórica seria a forma dos conotadores. (p. 96-97)

Resumindo, na denotação, há uma relação simples entre significante (chamado pelo linguista de "plano de expressão") e significado ("plano de conteúdo"), o que constitui um signo. Já na linguagem conotativa, esse mesmo signo comporta-se como um outro significante, relacionado, por sua vez, a outro significado. A conotação, nesse sentido, constituiria um uso expressivo do signo linguístico, ao passo que a denotação se fundamentaria na associação entre o significante e seu significado, que apontaria para o elemento extralinguístico que o signo representa.

Fica evidente que o significado da linguagem conotativa não é totalmente desvinculado do significado denotativo. Além disso, a compreensão da distinção proposta por Hjelmslev deixa claro o potencial polissêmico do signo, tendo em vista que uma mesma forma seria capaz de ter seus sentidos multiplicados.

A partir daí, Barthes pergunta "Como classificar os significados?" (BARTHES, 1971, p. 47). Segundo o autor, "a Linguística Estrutural, por mais avançada que esteja, não edificou ainda uma Semântica, isto é, uma classificação das formas do significado verbal" (p. 48). O significante "seria um mediador (material) do significado" (p. 52) e "o liame entre significante e o significado é contratual em seu princípio, mas esse contrato é coletivo, inscrito numa temporalidade longa (Saussure diz que "a língua é sempre uma herança"), e, consequentemente, naturalizado, de certo modo; (...)" (p. 53)

$\mathrm{O}$ estruturalismo priorizou, até certo ponto, o sentido denotativo, visto como básico, a partir do qual se desdobrariam sentidos conotativos. Embora não tenham sido abandonados, os estudos da conotação foram realizados por muitos estruturalistas, mas sob o enfoque da estilística ou da semiótica. 


\section{Ulmann e o esquema tripartido: nome, sentido e coisa}

Outro linguista que trabalhou com a noção de signo foi Stephen Ulmann. Em seus estudos, substitui a dicotomia significante/significado, proposta por Saussure, por um esquema tripartido: nome, sentido e coisa. (ULMANN, 1987, p. 119).

Figura 5. Modelo do signo para Ulmann

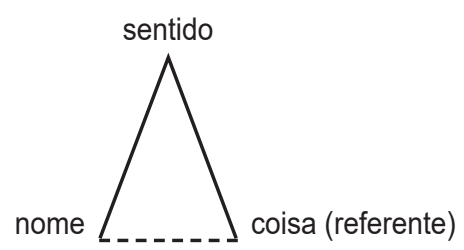

Fonte: Ulmann, 1987, p. 119

O nome seria o material fonético da palavra, ou seja, o significante proposto por Saussure; o sentido, a informação que o nome fornece ao interlocutor e, por fim, a coisa, o referente externo, não-linguístico. A linha pontilhada enfatiza a ideia, já defendida por Saussure, de que não existe uma relação direta entre um nome e um referente. $\mathrm{O}$ sentido seria o responsável pela inter-relação entre nome e referente. E a relação entre nome e sentido, recíproca e reversível, na qual um elemento evoca o outro, corresponderia, para Ulmann, ao significado. $\mathrm{O}$ linguista resume o significado em quatro aspectos: sentido, tom, sentimento e intenção, e trata das fontes de tonalidades emotivas, dos artifícios emotivos e da perda do significado emotivo.

Nessa perspectiva, os termos "significado" e "sentido" são efetivamente diferentes: o significado constitui um elemento semântico básico, capaz de gerar inúmeros matizes contextuais, que são, na verdade, os sentidos. A fronteira entre denotação e conotação, dessa forma, fica mais nítida, como salienta Marques:

(...) o significado básico seria a denotação da palavra. Junto com os demais matizes associativos de significados da palavra constitui a sua conotação. Em determinadas situações, o significado básico, descritivo e referencial prevalece. Em outras, o significado conotativo pode preponderar e, até, esvaziar a denotação de uma palavra criando-lhe sentidos novos, no que se tem chamado de processos de hipersemantização. (MARQUES, 2003, p.62) 
Fugindo um pouco à prática estruturalista, Ulmann vê o contexto como um elemento importante em relação ao significado, chegando a afirmar que o contexto pode ser determinante na fixação de um dado sentido. Porém, é importante enfatizar que a língua não é um decalque da realidade. Por exemplo, algumas palavras nomeiam fenômenos e seres que nem sempre existem. Além disso, há palavras gramaticais como conjunções, preposições etc. que apontam para a própria língua, não denominando necessariamente um ser de existência concreta.

Nesse sentido, para Ullmann, o significado não é resultado de uma correspondência natural entre nome e sentido, mas da tradição, da convenção, de um contrato firmado entre os indivíduos de uma sociedade. Para o linguista, o caráter vago e a opacidade das palavras desencadeiam a maior parte dos fatores emotivos que constituem a significação. Em algumas palavras, como os adjetivos, o elemento emotivo é parte integrante do significado, assim como também há casos em que as palavras perdem esse significado emotivo. A falta de "precisão" das palavras ocorre em função das mudanças de aplicação, o que muitas vezes gera ambiguidade, e em função da falta de fronteiras bem definidas no mundo extralinguístico.

Ullmann também explora a teoria do Campo Associativo. Essa teoria do campo lexical vem de Saussure (1977) que evidencia que a língua é uma estrutura na qual as palavras formam sistemas relacionados entre si. Segundo Saussure (1977),

(...) fora do discurso, as palavras que oferecem algo de comum se associam na memória e assim se formam grupos dentro dos quais imperam relações muito diversas. (p. 143)

Os grupos formados por associação mental não se limitam a aproximar os termos que apresentem algo em comum; o espírito capta também a natureza das relações que os unem em cada caso e cria com isso tantas séries associativas quantas relações diversas existam. Assim, em enseignement, enseigner, enseignons etc. (ensino, ensinar, ensinemos), há um elemento comum a todos os termos, o radical; todavia, a palavra enseignement (ou ensino) se pode achar implicada numa série baseada em outro elemento comum, o sufixo (cf. enseigment, armement, changement etc.; ensinamento, armamento, desfiguramento etc.); a associação pode se fundar também apenas na analogia dos significados (ensino, instrução, aprendizagem, educação etc.) ou, pelo contrário, na simples comunidade das imagens acústicas (por exemplo, 
enseignement e justement, ou ensinamento e lento). Por conseguinte, existe tanto comunidade dupla do sentido e da forma como comunidade de forma ou de sentido somente. Uma palavra qualquer pode sempre evocar tudo quanto seja suscetível de ser-lhe associado de uma maneira ou de outra. (p. 145-146)

Assim, dando continuidade a essa teoria, para Ullman (1987), o campo associativo de uma palavra é formado por uma rede de associações baseadas nas semelhanças, na contiguidade; umas surgindo entre os sentidos, entre nomes ou entre ambos. $\mathrm{O}$ campo associativo é aberto e algumas das associações podem ser subjetivas, como a linguagem figurada: metáforas, comparações, provérbios e idiomatismos.

\section{Pottier e os conceitos de sema e semema}

Outro estudioso, Bernard Pottier, herdeiro da tradição estruturalista, também trabalhou com o conceito de signo linguístico. Para ele, um signo também é composto de significado e significante. O primeiro elemento - o significado - pode ser decomposto em substância (traços semânticos) e em forma (traços classificatórios, de natureza gramatical). Além disso, ainda para o estudioso, a substância do significado de um elemento deve ser analisada e/ou compreendida em relação com outras unidades, ou seja, dentro de um contexto. Vejamos a palavra "cadeira":

Figura 6. Signo "cadeira"

\begin{tabular}{|l|l|}
\hline \multicolumn{1}{|c|}{ Substância de significado } \\
$\begin{array}{l}\text { Móvel utilizado para se } \\
\text { sentar, tem assento, pés, } \\
\text { encosto e serve para apenas } \\
\text { uma pessoa. }\end{array}$ & $\begin{array}{l}\text { Forma de significado } \\
\text { Substantivo comum, } \\
\text { concreto, feminino. }\end{array}$ \\
\hline \multicolumn{2}{|r|}{$\begin{array}{r}\text { Significante } \\
{[\mathrm{ka} \text { deirə] }]}\end{array}$} \\
\hline
\end{tabular}

Levando em consideração o contexto, a substância de significado de "cadeira" é delimitada por elementos do mesmo campo semântico, como banco, sofá, poltrona e outros. 
Outra contribuição de Pottier para o nosso estudo é o conceito de "sema". Segundo o linguista francês, o semema é a substância do significado e o sema são os traços semânticos que constituem o semema.

Assim, no exemplo dado anteriormente, "cadeira", "banco", "sofá" e "poltrona", em todas essas palavras há um semema comum, ou seja, todas dizem respeito a um "móvel utilizado para se sentar". O que vai diferenciá-las são os semas, ou seja, os traços específicos, distintivos que entram na composição desses sememas. Por exemplo, cadeira tem assento, pés, encosto e serve para apenas uma pessoa; banco tem assento, pés e pode servir para apenas uma pessoa, ou para várias pessoas; sofá tem assento, braços, pés, encosto e serve para mais de uma pessoa; poltrona tem assento, braços, pés, encosto e serve para apenas uma pessoa.

Como se vê, sofá se diferencia de poltrona porque serve para várias pessoas; poltrona se diferencia da cadeira convencional porque tem braços e revestimento; cadeira se diferencia de banco porque tem encosto e etc. Cada um desses traços diferenciadores constitui um sema.

Pottier identifica três espécies de semas: os específicos (expressam as características semânticas mais relevantes de uma palavra), os genéricos (permitem a inclusão das palavras em classes mais amplas) e os virtuais (também chamados de conotativos, atualizam-se no contexto, revestindo a palavra com várias nuances). $O$ conjunto de semas básicos (específicos e genéricos) e virtuais de uma palavra constitui seu semema ou semantema. Nesse sentido, temos o seguinte esquema:

Figura 7. Semema

\begin{tabular}{|l|c|c|c|}
\hline Denotação & Semas específicos & Semas genéricos & \\
\cline { 1 - 2 } Conotação & \multicolumn{2}{|c|}{ Semas virtuais } & \multirow{2}{*}{ SEMEMA } \\
\hline
\end{tabular}

Aplicando esses conceitos, teríamos, por exemplo, para "rato" os semas específicos animal, mamífero, roedor etc.; os semas genéricos animado, não humano; e os semas virtuais ladrão, traiçoeiro, nocivo etc. Por exemplo, é com base nesses 
semas virtuais que a revista Veja, em várias edições, dentre as quais selecionamos uma, associa um político corrupto a um rato:

Figura 8. "Corruptos" (Veja, 25/05/2005)

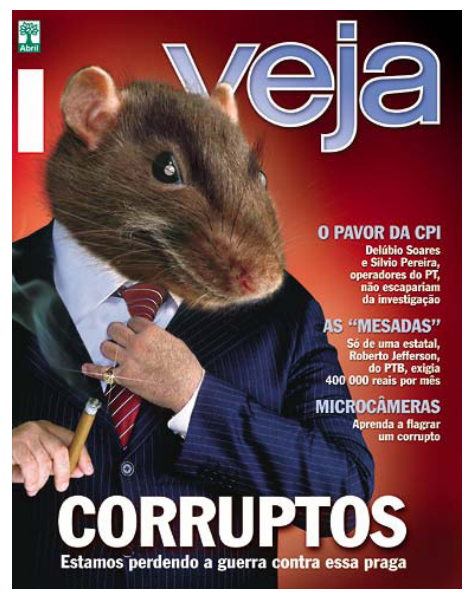

Figura 9. "Temporada de caça aos ratos" (Veja, 25/05/2005, p. 46-47)

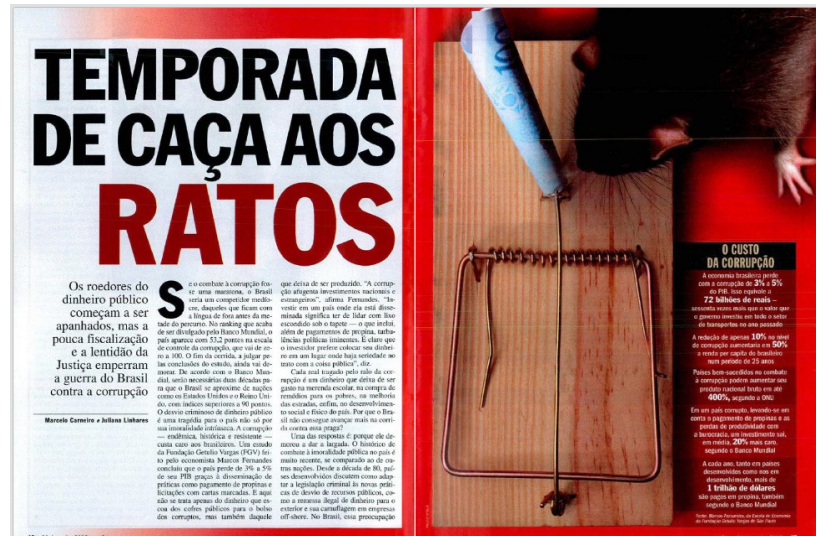

A manchete "Corruptos", no plural, faz referência aos políticos que não agem com idoneidade, alvos de investigação, assemelhando-se a ratos, animais traiçoeiros, que agem sorrateiramente. Já o subtítulo que segue à manchete tem o substantivo feminino "praga" associado ao animal que é exibido em destaque na capa - o rato. Assim, a Veja diz explicitamente que um político é um rato e, consequentemente, uma praga. 
Dando continuidade ao aprofundamento da teoria de Saussure, veremos a distinção entre sentido de língua e sentido de discurso, proposta por Charaudeau.

\section{Charaudeau e a distinção entre sentido de língua e sentido de discurso}

A Semiolinguística é uma teoria da Análise do Discurso, criada pelo pesquisador da Universidade Paris XIII, Patrick Charaudeau.

EmSemiolinguística, Sémio - vem de sémiosis - sinaliza que a construção do sentido e sua configuração se fazem por meio de uma relação forma-sentido; já o termo - linguística lembra que a forma de ação pretendida pelo sujeito-comunicante é, sobretudo, constituída por um material linguageiro oriundo das línguas naturais. (CHARAUDEAU, 1995, p. 98)

Por meio de signos verbais e/ou não verbais o sujeito é capaz de significar o mundo para o outro. Isso significa dizer que a comunicação parte de um processo de semiotização de mundo elaborado através de um processo de transformação entre o mundo a ser significado e o mundo significado; e de um processo de transação (base da construção do contrato de comunicação) entre o sujeito comunicante e o sujeito interpretante-destinatário (CHARAUDEAU, 1995, p. 101).

Segundo Charaudeau (2008, p. 24), o ato de linguagem tem uma dupla dimensão ou um duplo valor: o explícito e o implícito.

O explícito testemunha uma atividade estrutural da linguagem: a simbolização referencial. Assim, enunciados como "Fecha a porta", "Abra a porta" remetem-nos à realidade que nos rodeia (atividade referencial), conceituando-a (atividade de simbolização).

Já o implícito testemunha uma atividade serial da linguagem: a significação. O mesmo enunciado "Fecha a porta", levando-se em consideração as circunstâncias de produção e a intencionalidade do sujeito que comunica, pode enunciar diferentes significados. Por exemplo, pode enunciar "Eu estou com frio", ou "Eu quero lhe contar um segredo", ou que "Os barulhos do corredor estão me incomodando" etc.

Na dimensão explícita, as paráfrases são estruturais, ou seja, excludentes, não concomitantes à mesma instância de fala. Por exemplo, não é possível a estrutura "Fecha a porta porque 
abra a porta". Já na dimensão implícita, as paráfrases são seriais, não excludentes. Por exemplo, "Fecha a porta porque estou com frio" é perfeitamente possível.

Assim, segundo Charaudeau (2008, p. 25),

é um jogo construtor da significação de uma totalidade discursiva que remete a linguagem a si mesma como condição de realização dos signos, de forma que estes não signifiquem mais por si mesmos, mas por essa totalidade discursiva que os ultrapassa: (...) Significação. [Grifo do autor]

Para Charaudeau (2008, p. 25), "sentido" de uma palavra é aquele fornecido, normalmente, pelos dicionários, em situação fora do contexto. Já a "significação" de um texto ou de uma conversa é obtida apenas em situação de emprego, no discurso, ou seja, na língua em uso. Nessa perspectiva, a significação não é concebida como uma operação de adição entre signos que teriam, cada um isoladamente, um valor autônomo. Pelo contrário, "a significação é uma manifestação linguageira que combina signos em função de uma intertextualidade particular e que depende de Circunstâncias de discurso particulares." (CHARAUDEAU, 2008, p. 35). Além disso, segundo o autor,

longe de conceber que o sentido se constituiria primeiro de forma explícita em uma atividade estrutural e, em seguida, seria portador de um implícito suplementar no momento de seu emprego, dizemos que é o sentido implícito que comanda o sentido explícito para construir a significação de uma totalidade discursiva. (CHARAUDEAU, 2008, p. 26)

Dessa forma, quando se pensa, por exemplo, na palavra "laranja", a ideia ou conceito "fruta" não é o significado propriamente dito do signo, mas um elemento de sentido que pode ser trazido por um determinado significante.

O fenômeno linguageiro, assim, é constituído por um duplo movimento:

o primeiro deles é exocêntrico, ou seja, movido por uma força centrífuga que obriga todo ato de linguagem (e, portanto, todo signo) a se significar em uma intertextualidade que é como um jogo de interpelações realizado entre os signos, no âmbito de uma contextualização que ultrapassa amplamente - seu contexto explícito. A esse movimento, corresponde a atividade serial que garante a produção da significação do discurso.

O segundo movimento é endocêntrico, ou seja, movido por uma força centrípeta que obriga o ato de linguagem (e, logo, os 
signos que o compõem) a ter significado, ao mesmo tempo, em um ato de designação da referência (no qual o signo se esgota em função de troca) e em um ato de simbolização; nesse ato o signo se instala dentro de uma rede de relações com outros signos (rede comandada pela atividade serial) e se constitui como valor de diferença. Corresponde a esse movimento a atividade estrutural que garante a construção do sentido da Simbolização referencial. (CHARAUDEAU, 2008, p. 27)

Nesse sentido, esse duplo movimento mostra a linguagem como um fenômeno conflitual, já que

a atividade serial põe em causa, incessantemente, as tentativas que a atividade estrutural empreende para fixar o signo em um lugar definitivo de reconhecimento do sentido; de outro lado, a atividade estrutural, por sua vez, tenta fixar, "congelar", o sentido comandado pela atividade serial. [Grifos do autor] (Op. cit., p. 27)

O explícito é sempre incompleto, pois apresenta-se na interpretação "como uma superfície lacunar repleta de espaços vazios de sentido". (CHARAUDEAU, 2008, p. 27)

O implícito, ligado às Circunstâncias de Discurso, determina a significação do ato de linguagem. As Circunstâncias de Discurso englobam as práticas sociais partilhadas e os filtros construtores de sentido.

Dessa forma, para Charaudeau (2008, p. 33), o signo não é uma "unidade autônoma de sentido, pois ele também é preenchido por um saber que depende da expectativa particular de cada ato de linguagem e, portanto, dos filtros construídos e colocados pelo Enunciador e pelo Interpretante". Assim, uma marca não é um signo, mas é a combinatória das marcas que, no contexto, faz o signo.

O signo linguístico apresenta-se, do ponto de vista de seu sentido, sob a dupla face de uma qualificação referencial - "valor de designação do signo que atribui uma carga semântica a uma determinada parte do mundo físico (...)" e de uma funcionalidade - "valor de uso do signo, que depende de um determinado universo de discurso (...)" (CHARAUDEAU, 2008, p. 34). Assim, "não há 'unicidade de saber', nem 'pluralidade de saber' sobre um signo (a polissemia), mas esta pluralidade existe porque estamos sempre diante de vários signos" (CHARAUDEAU, 2008, p. 34). 
Dessa forma, se uma palavra é definida fora de um contexto, como, por exemplo, "olho" - "parte do rosto" ou "órgão da visão", "isso ocorre somente em função de um hábito cultural (registrado e imposto pelo dicionário) que privilegiou um de seus usos, e não porque essa definição será o valor unitário e absoluto do signo" (CHARAUDEAU, 2008, p. 34).

Porém, além dos valores de uso, há constantes de sentido que aparecem pontualmente.

Essas constantes de sentido se constroem em razão do emprego de palavras em contextos semelhantes e em contextos diferentes. (...) Se podemos reconhecer o traço de "redondez" como sendo um dos componentes de olho - pois uma marca linguística pode ser portadora de vários componentes - isso ocorre como o resultado de um determinado saber que se constitui em razão dos diferentes usos que se valeram desse traço. Denominamos esse saber Núcleo metadiscursivo (NmD). (Charaudeau, 2008, p. 35)

Assim, cada uma das unidades morfêmicas da manifestação linguageira não é uma unidade-signo portadora de um sentido pleno. Pelo contrário, cada uma dessas unidades contribui, com o auxílio do seu Núcleo metadiscursivo, para formar um signo na significação do ato de linguagem. Por exemplo, a palavra "laranja" não é uma unidade morfêmica plena de todos os sentidos que podemos lhe atribuir. Dependendo do contexto, pode vir a ter a significação de "fruta", pode significar "indivíduo que se presta, consciente ou inconscientemente, a participar de golpes para outros indivíduos, normalmente, poderosos".

Figura 10. “Mais laranjas de Renan" (Veja, 08/08/2007)

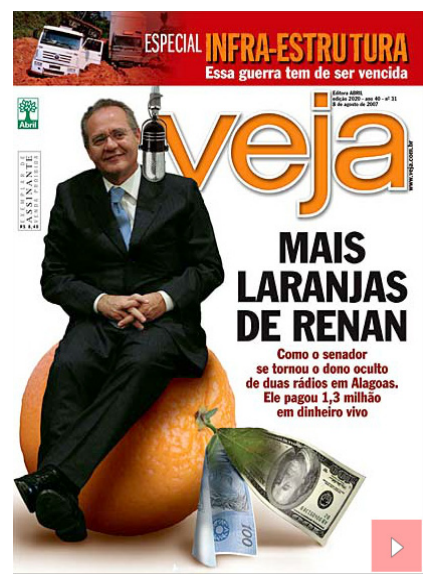


Figura 11. “O rei dos laranjas” (Veja, 18/12/2013)

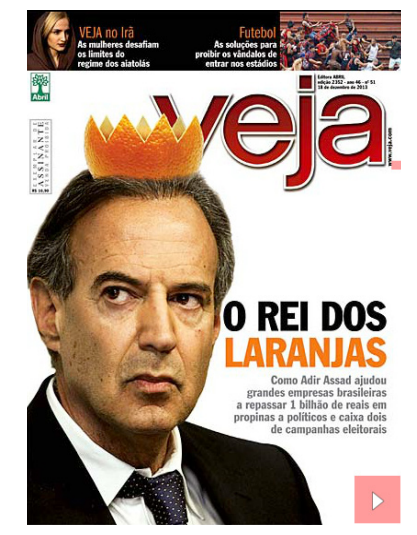

Nas capas da Veja (Fig. 10 e 11), por mais que se faça uma relação com a fruta laranja, como se vê na imagem e no uso da cor, o objetivo da revista é atualizar o segundo sentido já descrito, o de indivíduo que se presta a participar de golpes para outros indivíduos.

Nesse sentido, Charaudeau (2008, p. 36) afirma que “(...) o signo é algo complexo, que se constrói na instância linguageira em função de uma determinada expectativa discursiva; esta expectativa convoca marcas portadoras de um determinado NmD. (...)". Assim, é possível afirmar que o sentido dicionarizado é somente mais um, o mais usual que a palavra pode significar e não o primeiro.

\section{Finalizando...}

Sem dúvida, os estudos linguísticos atuais seguiram várias direções, definindo diversas correntes e tendências teóricas. De forma direta ou indiretamente, todos esses estudos nascem a partir dos ensinamentos de Saussure, criador e precursor da linguística estrutural. E, nesse contexto, a análise do discurso, aqui representada pela Semiolinguística, busca resgatar a exterioridade intrínseca à linguagem que fora ignorada, por questões metodológicas, pelo corte saussuriano. O sujeito que interpreta um texto não busca apenas o sentido intrínseco das palavras (significado referencial), mas seu valor social e seu peso na troca interativa. 


\section{REFERÊNCIAS}

ALMEIDA, Carlos Cândido de. Elementos de linguística e semiologia na organização da informação. 1. ed. São Paulo: Cultura Acadêmica, 2011.

BARTHES, Roland. Elementos de semiologia. Trad. Izidoro Blikstein. São Paulo: Cultrix, 1971.

CHARAUDEAU, Patrick. Linguagem e discurso: modos de organização. Coord. da equipe de trad. Ângela M. S. Corrêa; Ida Lúcia Machado. São Paulo: Contexto, 2008.

-----. Les conditions de compréhension du sens de discours. In: Anais do I Encontro Franco-Brasileiro de Análise do Discurso. Rio de Janeiro: UFRJ, 1995, pp. 9-16.

HJELMSLEV, Louis. Prolegômenos a uma teoria da linguagem. Trad. J. Teixeira Coelho Neto. São Paulo: Perspectiva, 1975.

MARQUES, Maria Helena Duarte. Iniciação à semântica. 6. ed. Rio de Janeiro: Jorge Zahar, 2003.

POTTIER, Bernard. Linguística geral: teoria e descrição. Trad. Walmírio Macedo. Rio de Janeiro, 1978.

SAUSSURE, Ferdinand de. Curso de linguística geral. Trad. Antônio Chelini, José Paulo Paes e Izidoro Blikstein. 8. ed. São Paulo: Cultrix, 1977.

ULLMANN, Stephen. Semântica: uma introdução à ciência do significado. Trad. J. A. Osório Mateus. Fundação Calouste Gulbenkian, 1987.

\section{WEBLIOGRAFIA CONSULTADA}

REVISTA VEJA. Disponível em < https://acervo.veja.abril.com. br/\#/editions> Acesso em agosto de 2017. 


\begin{abstract}
The sign to text, from language to discourse: from Saussure to Charaudeau

This article aims, at first, to make a few reflections on the concept of linguistic sign postulated by Saussure in order to approach other thoughts that deepened and broadened the studies of the Swiss linguist, such as the definitions presented by Hjelmslev, Ullmann and Pottier. After this structuralist approach, our second aim is to find a link between Saussure's ideals and discourse analyst Patrick Charaudeau's proposals in distinguishing between sense of language and sense of discourse. This study is important because the problems involving the reading of any text, i.e. the "from language to discourse" activity, inevitably touch upon the concept of linguistic sign, which is distinctly approached by the various currents.
\end{abstract}

Keyword: Sign. Language. Discourse. Reading. 